\title{
Vozes argumentativas e \\ posicionamento autoral na produção escrita escolar
}

\author{
Adriana Nogueira Accioly Nóbrega ${ }^{a}$ \\ Adriana Rodrigues de Abreu
}

\begin{abstract}
Resumo
Neste artigo, abordamos a produção textual escolar, tendo em vista a possível relação entre vozes e posicionamento argumentativo, e analisamos como tais vozes refletem e refratam o posicionamento ideológico do aluno-escritor. Nosso objetivo é discutir o diálogo existente entre vozes discursivas e argumentação na escrita escolar e identificar como o discurso dialógico (re)produz ideologias de uma dada cultura. Para tanto, recorremos à abordagem sociodiscursiva proposta pelo Círculo de Bakhtin, em interface com fundamentos teóricos da perspectiva social de argumentação. Tomando por base uma metodologia qualitativa de pesquisa, dois textos dissertativo-argumentativos, pertencentes a um corpus de 50 redações, foram selecionados e posteriormente analisados, a fim de ilustrarmos como os discursos produzidos trazem ideologias que compõem o posicionamento autoral. Os resultados indicam que as redações são permeadas por inúmeras vozes, que são utilizadas para a construção dos argumentos e do ponto de vista do escritor.
\end{abstract}

Palavras-chave: Produção textual; Vozes; Argumentação; Posicionamento autoral

\footnotetext{
a PUC-Rio - Pontifícia Universidade Católica, adriana.nnobrega@gmail.com

b PUC-Rio - Pontifícia Universidade Católica, adrianarodriguess@yahoo.com.br
} 


\section{Palavras iniciais}

Estudar o discurso no contexto educacional, seja em sua modalidade oral ou escrita, é uma ação fundamental para compreendermos as relações dialógicas que nele se estabelecem. Assim, refletir sobre as diferentes práticas discursivas nas quais estamos inseridos em sala de aula torna-se essencial para que, como educadores e pesquisadores, possamos contribuir para uma investigação do discurso pedagógico sob uma ótica reflexiva.

Em nossa pesquisa, buscamos esse olhar questionador ao analisarmos a prática escrita escolar como forma de identificação dos diferentes enunciados que circulam no contexto educacional. Ao voltarmos nossa análise para a produção textual discente, estamos interessadas em observar, sobretudo, o universo de vozes que permeia os textos de um grupo de alunos do terceiro ano do Ensino Médio e sua influência para a formação do posicionamento argumentativo dos alunos-escritores. Com base em uma abordagem dialógica de linguagem, entendemos que os textos são elaborados por meio de enunciados originários de contextos sociais distintos, sendo todos compostos por vozes ${ }^{1}$ que emergem ao longo de sua produção (BAKHTIN/ VOLOCHINOV, 1990; BAKHTIN, 2003).

A perspectiva sociodiscursiva adotada neste estudo nos permite abordar os textos a partir da noção dialógica de linguagem proposta pelo Círculo de Bakhtin. Nesse contexto, a linguagem é estabelecida em interações específicas entre sujeitos, que influenciam e são influenciados pela palavra de muitos outros sujeitos. Por essa razão, consideramos que não há diálogo sem possibilidade de resposta, pois estamos constantemente respondendo a enunciados anteriores e criando novos em resposta a discursos que ainda estão por vir.

Partimos da premissa de que todo texto é permeado por inúmeras vozes, em constante diálogo com o ambiente no qual ele foi produzido, já que os enunciados são influenciados por um dado contexto situacional. Alinhadas a tal pressuposto, para a realização da pesquisa relatada neste artigo, trazemos,

${ }^{1}$ Neste artigo, os termos "vozes", "vozes sociais" e "vozes discursivas" são tratados como análogos e utilizados de forma intercambiável. em interface com a teoria dialógica de linguagem, os estudos de argumentação de acordo com uma visão social, ou seja, de construção ativa e criativa, tanto por parte do escritor quanto do leitor. 
A noção de argumentação como atividade estruturante de todo e qualquer discurso (BRETON, 2003; KOCH, 2011) nos leva a compreender a escrita argumentativa como um espaço para a formulação de argumentos pautados em enunciados sociais, originários de contextos específicos de interação. Por isso, defendemos que os textos são compostos por vozes argumentativas que contribuem para a formação do posicionamento autoral nas redações investigadas. Conforme veremos adiante na análise dos dados, mesmo estando as redações selecionadas aquém de alguns padrões esperados quanto ao uso de normas gramaticais e quanto à formação da estrutura retórica do texto, existe o domínio da estrutura argumentativa por parte dos alunos-escritores. Além disso, é possível notarmos nos textos analisados um forte posicionamento autoral, que se dá na produção de discursos ideológicos circulantes na sociedade como um todo.

Portanto, temos como objetivos da pesquisa discutir o diálogo existente entre vozes e argumentação na escrita escolar e observar como a "dinâmica do processo de interação das vozes sociais" (FARACO, 2013, p. 61) (re)produz ideologias de uma dada cultura. A fim de alcançar nossos propósitos de análise, traçamos as seguintes perguntas de pesquisa: (1) Como vozes e posicionamento argumentativo se relacionam na produção textual estudada? e (2) De que forma as vozes identificadas refletem e refratam o posicionamento ideológico do aluno-escritor? Com o intuito de responder a tais questionamentos, apresentamos nossa reflexão acerca da prática da escrita escolar em consonância com uma visão teórica que privilegie a linguagem e a argumentação como conceitos vinculados ao contexto no qual são (re)produzidas, como apresentamos a seguir.

\section{Perspectiva dialógica e argumentação}

Na perspectiva dialógica de linguagem proposta por Bakhtin e seu Círculo, a língua é um fato social, cuja existência se fundamenta nas necessidades de comunicação, que, por sua vez, estão atreladas às estruturas sociais. Não sendo um produto pronto e acabado transmitido de geração em geração, a língua dura e perdura dentro de um processo evolutivo inin- 
terrupto. Bakhtin situa a língua como um fenômeno social da interação verbal, pois:

(...) a verdadeira substância da língua não é constituída por um sistema abstrato de formas linguísticas nem pela enunciação monológica isolada, nem pelo ato psicofisiológico de sua produção, mas pelo fenômeno social da interação verbal, realizada através da enunciação ou das enunciações. A interação verbal constitui assim a realidade fundamental da língua. (BAKHTIN/ VOLOCHINOV, 1990, p. 123)

Desse modo, a linguagem na teoria bakhtiniana é um fenômeno social, constituída por signos ideológicos que compõem o sistema linguístico. A ideologia é, assim, fundamental para o entendimento da natureza da língua, uma vez que ela não pode ser desassociada de sua estrutura social tampouco de seu conteúdo ideológico.

Segundo Nóbrega (2003, p. 61), “o discurso verbal está ligado à vida e só nela encontra seu verdadeiro sentido; as falas da vida encontram-se estreitamente ligadas às ações cotidianas.". Esse caráter vivo e dinâmico da linguagem, que deve ser considerada em sua totalidade, torna-se fundamental quando investigamos a língua como uma prática social discursiva, composta por atores sociais imersos em uma dada realidade. Como Bakhtin, apontamos que a comunicação verbal precisa ser construída a partir de sua relação com situações concretas desenvolvidas em diferentes atividades sociais. Por esse motivo, pretendemos analisar como a escrita escolar constitui subjetividades ao (re)produzir o discurso de uma determinada cultura, já que, como afirma Miotello:

Afinal, para Bakhtin o sujeito não se constitui apenas pela ação discursiva, mas todas as atividades humanas, mesmo as mediadas pelo discurso, oferecem espaço de encontros de constituição da subjetividade, pela constituição de sentidos. (MIOTELLO, 2005, p. 171)

Levando em conta a importância das interações sociais no pensamento bakhtiniano, podemos dizer que todo enunciado sempre se remete para o outro, o que constitui o princípio de alteridade. $\mathrm{O}$ enunciado como totalidade linguística que “'transcende' os limites do próprio texto" (RODRIGUES, 2005, p.157, aspas simples no original) não pode existir se não houver 
um direcionamento para alguém, pois o mesmo se produz em um contexto social, em que "o ouvinte ou leitor é assim um outro - presença individual ou imagem ideal de uma audiência imaginária." (FREITAS, 2000, p. 135). A comunicação verbal se dá no diálogo entre indivíduos e o enunciado deve ser entendido como a unidade real da comunicação discursiva, seja como matéria linguística ou contexto enunciativo. Assim como o enunciado, o texto é tido por Bakhtin como um fenômeno sociodiscursivo e, de acordo com Barros:

Sua [Bakhtin] definição de enunciado aproxima-se da concepção atual de texto. O texto é considerado hoje tanto como objeto de significação, ou seja, como um "tecido" organizado e estruturado, quanto como objeto de comunicação, ou melhor, objeto de uma cultura, cujo sentido depende, em suma, do contexto (...). O texto-enunciado recupera estatuto pleno de objeto discursivo, social e histórico. (BARROS, 1999, p. 1, aspas no original)

O diálogo proposto por Bakhtin ocorre entre os textos que circulam em um determinado contexto, seja esse imediato ou amplo. O pensamento do autor adota um olhar voltado para as relações dialógicas que constituem o sujeito em seu diálogo com o outro. O cerne da teoria sociodiscursiva concentra-se na interação verbal e em seu caráter dialógico, já que qualquer enunciado é composto por ecos dos sujeitos do discurso e pelas tonalidades dialógicas, permeáveis à expressão do autor (BAKHTIN, 2003, p. 299). Contudo, existem textos, denominados monológicos, que pretendem ocultar os diálogos que os constituem, em oposição a textos dialógicos, que são tecidos por inúmeras vozes sociais confrontadas nas "mais diferentes refrações sociais expressas em enunciados de qualquer tipo e tamanho" (FARACO, 2013, p. 62).

O dialogismo é, portanto, o princípio constitutivo e organizador da linguagem, sendo o diálogo a forma básica de comunicação verbal. Não há como pensar a linguagem sem se observar a relação dialógica constituinte de qualquer discurso. Um enunciado nunca será completamente novo, ele estará, de algum modo, vinculado àqueles que o precederam ou ainda aos que o sucederão, em constante intertextualidade e diálogo com os diversos textos de uma cultura. Essa intertextualidade na obra de Bakhtin é, antes de tudo, "a 'intertextualidade' interna 
das vozes que falam e polemizam no texto, nele reproduzindo o diálogo com outros textos." (BARROS, 1999, p. 4).

Considerando que um discurso sempre está atrelado a algo já dito, é importante destacarmos que o conceito de voz em Bakhtin se refere à "consciência falante presente nos enunciados." (JUNQUEIRA, 2003, p. 33). Tal consciência se constrói a partir do processo de enunciação em um contexto específico e por isso sempre traz uma visão de mundo, um juízo de valor. Consequentemente, o conceito de voz pode ser visto como a presença de diferentes consciências (discursos) que entremeiam os textos pesquisados (ABREU, 2013).

É na dinâmica das relações dialógicas que ocorre o entrecruzamento das vozes sociais que compõem o discurso. Segundo Faraco (2013, p.58), para Bakhtin, é "na dialogização das vozes sociais, isto é, no encontro sociocultural dessas vozes" que essa dinâmica se concretiza em uma cadeia que provoca inúmeras respostas, tais como "adesões, recusas, aplausos incondicionais, críticas, ironias, concordâncias e dissonâncias (...). O universo da cultura é intrinsicamente responsivo, ele se move como se fosse um grande diálogo." (FARACO, 2013, p. 59, grifos no original). No caso do presente estudo, entendemos que a produção textual observada é uma resposta aos textos motivadores expostos na proposta de redação aplicada aos participantes, seja, dentre outros aspectos, pela aceitação, reprodução ou recusa das ideologias presentes no contexto imediato da atividade pedagógica, assim como no contexto amplo da realidade de cada autor.

A natureza dialógica e ideológica da linguagem nos permite dizer que todas as vozes surgem no emprego vivo da palavra em um determinado contexto social. No que tange à prática argumentativa, as vozes discursivas apresentam-se importantes para a elaboração dos argumentos e do posicionamento autoral que, provenientes do embate entre muitas vozes sociais, são gerados em um universo responsivo caracterizado "pela posição do autor como regente do grande coro de vozes que participam do processo dialógico." (BEZERRA, 2005, p. 194).

O conflito de vozes existente nos enunciados revela um sentido ideológico ou vivencial e colabora para a proposição de argumentos que irão manter o ponto de vista do autor. Em relação à produção textual escolar, observamos que, geralmente, os alunos utilizam as vozes mais ligadas as suas experiências 
pessoais, sugerindo que os argumentos são formados por discursos que fazem parte da realidade imediata ou ampla do aluno-escritor. Suas palavras, povoadas por ideologias, expressam avaliações positivas ou negativas em relação ao mundo e as suas práticas cotidianas, confirmando que a língua, em sua essência, apresenta uma natureza argumentativa inseparável de seu conteúdo ideológico.

A perspectiva sociodiscursiva de linguagem nos permite tratar a argumentação como um processo de construção ativa - isto é, como atividade social -, em que o posicionamento do escritor assim como o do leitor parte do diálogo com o discurso do outro. $\mathrm{O}$ ato de argumentar, então, está relacionado às vozes presentes no contexto cultural e é constituído por discursos ideológicos que colaboram para a persuasão e para o convencimento do outro.

A partir da constatação de que o "eu" se constitui verbalmente sobre a base do "nós" (BRAIT, 1999, p. 17), associamos a argumentação ao princípio dialógico da linguagem, pois os argumentos são criados por um "eu" (autor/enunciador) com suas crenças e experiências pessoais, mas que argumenta com base nos enunciados dos "outros" ou do "nós" (leitor/ enunciatário real ou imaginário), com os quais teve contato em sua esfera de comunicação discursiva. Ao produzirmos um discurso, sempre nos apropriamos da língua com o objetivo de interagir socialmente, pois, ao nos constituirmos como "eu" estamos constituindo, ao mesmo tempo, o "outro", que é por sua vez constitutivo do próprio "eu" (KOCH, 2011). Portanto, é na (inter)relação do "eu" com o "nós" que produzimos textos argumentativos formados por marcas avaliativas originárias de enunciados concretos e entrelaçados por múltiplas vozes discursivas. A ligação existente entre o "eu" individual com o "nós" coletivo será apontada no corpus desta pesquisa, já que as redações selecionadas para análise revelam o engajamento responsivo de seus autores à questão da importância do domínio da escrita para a inclusão social e evidenciam a intertextualidade de seus enunciados com a multiplicidade de discursos que circulam nas diversas esferas de atividades humanas nas quais os alunos se inserem.

A possível interface entre os princípios teóricos bakhtinianos e os trabalhos de argumentação desenvolvidos por Koch (2011) e Breton (2003) nos permite propor que o ato de 
2 O conceito de "ponto de argumentação" foi sugerido por Abreu (2013), coautora deste artigo, em sua dissertação de mestrado, tendo sido parte de seu capítulo sobre argumentação incorporada a este trabalho. A dissertação está vinculada ao Projeto de Pesquisa Escrita e inclusão social: análise da (re) construção identitária no Ensino Médio, desenvolvido na PUC-Rio, coordenado pela Professora Adriana Nogueira Accioly Nóbrega, autora deste artigo. argumentar é uma prática estruturante de todo e qualquer discurso, em seus mais diferentes usos e funções. Argumentar é, portanto, comunicar-se, dirigir-se a alguém, isto é, ao outro (imaginário ou real) com intuito de sugerir boas razões para compartilhar uma opinião (BRETON, 2003), já que, de acordo com Koch (2011), é por meio da argumentação que geramos sentidos ideológicos de avaliação e crítica, formando juízos de valor. A autora entende que "a interação social por intermédio da língua caracteriza-se, fundamentalmente, pela argumentatividade" (KOCH, 2011, p. 17) e, alinhada a Bakhtin, aponta que todo e qualquer discurso é ideológico e, portanto:

(...) o ato de argumentar, isto é, de orientar o discurso no sentido de determinadas conclusões, constitui o ato linguístico fundamental, pois a todo e qualquer discurso subjaz uma ideologia, na acepção mais ampla do termo. A neutralidade é apenas um mito: o discurso que se pretende "neutro", ingênuo, contém também uma ideologia - a da sua própria objetividade. (KOCH, 2011, p. 17, negrito e aspas no original)

É possível concluir que, ao elaborar seus argumentos, o sujeito tem a intenção de influenciar o comportamento do outro, a fim de que alguém compartilhe as suas opiniões. Tais argumentos são expostos pelo uso de escolhas léxico-gramaticais e semânticas e são permeados por elementos avaliativos que compõem a linguagem. As avaliações que sustentam os momentos de argumentação constituem os pontos de argumentação² (ABREU, 2013) - ideias apresentadas ao longo do texto que ajudam a defender o posicionamento geral (tese) do escritor, podendo contribuir para o aumento da força argumentativa no posicionamento autoral.

Uma das funções da argumentação é modificar o contexto de recepção de uma realidade cultural para poder ali introduzir uma opinião (BRETON, 2003). A modificação desse contexto se realiza em etapas, que buscam dar forma ao real comum entre os participantes da interação e apoiar a manutenção de uma negociação entre esses participantes quanto à opinião exposta. Tal acordo é realizado por alguém que tem autoridade para fazê-lo e que o torne verossímil, seja por sua competência, experiência ou testemunho, ou por pressupostos comuns que são utilizados com o intuito de avivar um pensa- 
${ }^{3}$ Recorte do Projeto de Pesquisa Escrita e inclusão social: análise da (re)construção identitária no Ensino Médio, desenvolvido na PUC-Rio.

${ }^{4}$ Os textos analisados foram mantidos em sua versão original, sem correções ou alterações.

${ }^{5}$ A proposta de redação aplicada ao grupo investigado encontra-se no Anexo, ao final deste artigo. mento comum, constituindo-se por meio de opiniões, valores e pontos de vista compartilhados.

Ao trazer para o seu texto os argumentos de autoridade ou aqueles ligados a opiniões comuns, por exemplo, o escritor gera discursos perpassados por ideologias que fazem (ou já fizeram) parte de enunciados de outros enunciadores e que passam a compor o seu posicionamento autoral. Por esse motivo, ressaltamos que as vozes analisadas nos textos desta pesquisa são argumentativas, já que ajudam na constituição do ponto de vista do autor e compõem os argumentos por ele trazidos.

\section{Vozes e argumentação: percurso metodológico e análise dos dados}

Este estudo ${ }^{3}$ fundamenta-se no paradigma de pesquisa qualitativa e dialógica (DENZIN e LINCOLN, 2006; BAKHTIN, 2003) de acordo com os pressupostos teórico-discursivos do Círculo de Bakhtin. Por meio da análise de redações produzidas por um grupo de alunos do terceiro ano do Ensino Médio, pretendemos identificar e analisar as vozes discursivas que permeiam os textos e discutir suas possíveis contribuições para a construção dos argumentos e do posicionamento autoral.

Para o processo de geração dos dados, elaboramos uma proposta de produção textual, posteriormente aplicada aos alunos-participantes, que adotou os critérios da prova de redação do Enem (Exame Nacional do Ensino Médio) e os de uma renomada universidade particular do Rio de Janeiro, em 2012. $\mathrm{Na}$ ocasião, ambas as provas apresentavam em sua estrutura dois ou três textos motivadores de diferentes fontes e uma imagem. Seguindo o objetivo de saber a opinião de nossos alunos sobre a relação comumente estabelecida entre "escrita e inclusão social" - e que vozes construíam o posicionamento autoral e ideológico desses alunos-escritores -, a atividade teve como suporte: (i) três fragmentos de textos que versavam acerca da escrita e sua relação com a inclusão social; (ii) uma charge que retratava a conversa entre um aluno e sua professora sobre o uso de diferentes variedades da língua portuguesa e (iii) a pergunta: "Qual é a sua posição sobre o ensino da escrita em língua portuguesa na escola e sua importância (ou não) para a inclusão social?" 
No total, foram gerados 50 textos redigidos por alunos de duas turmas de um colégio de formação geral, situado no município de São Gonçalo, no estado do Rio de Janeiro. A leitura detalhada das redações nos levou à observação das vozes mais sobressalentes e sua ligação na construção dos pontos de argumentação e formação do posicionamento argumentativo do aluno-escritor. Devido à extensão do corpus, trazemos para apresentação e discussão neste artigo apenas dois textos, cuja análise pretende ilustrar o que é recorrente no corpus como um todo.

É importante ressaltar que temos consciência de que a própria proposta de redação é constituída por vozes sociais, visto que os textos motivadores apresentavam opiniões vinculadas ao discurso de um artigo acadêmico, de um(a) participante do contexto escolar e de uma postagem realizada em um blog, (re) produzindo ideologias de determinados contextos culturais. Nos textos motivadores, notamos que o posicionamento dos autores criaram relações dialógicas, ou seja, de sentido, produzidas por vozes ideológicas relacionadas: à gramática tradicional, ao preconceito linguístico e social, ao senso comum e ao discurso pedagógico, dentre tantas outras possíveis.

As duas redações que apresentamos adiante como instanciações de nossa investigação são permeadas por vozes que formam pontos de argumentação. A análise dos textos aponta para o fato de que as vozes discursivas podem evidenciar marcas ideológicas apreciativas que constroem o ponto de vista dos escritores quanto ao tema: a precariedade da qualidade educacional no país (Redação 1: "O valor da Educação") e a crença na responsabilidade quase que exclusiva da escola na formação do sujeito (Redação 2: "O bom português").

Seguindo uma análise de base sociodiscursiva, reforçamos a noção de texto como objeto dialógico de comunicação e de argumentação como atividade estritamente social, composta por vozes provenientes de diferentes discursos ideológicos. Portanto, mais do que identificar e nomear as vozes que perpassam a escrita escolar investigada, desejamos discutir como essas contribuem para a argumentação e como colaboram para a estruturação do posicionamento do aluno-escritor.

A leitura dos textos nos permite afirmar que a escrita argumentativa do grupo em questão é formada por vozes sociais, 
provenientes, entre outros, do discurso presente em gramáticas tidas como tradicionais, bem como de posicionamentos marcados pelo senso comum e pelo preconceito linguístico e social. Percebemos também que o dialogismo se formula em enunciados focados na experiência particular do autor ou são dirigidos ao outro (participante ou não da interação discursiva), quando há o posicionamento autoral em relação a diferentes questões da sociedade, propostas a partir de vivências dos escritores.

No caso da Redação 1, a seguir, o aluno (enunciador) inicia seu texto com a constatação ideológica - comumente aceita e reproduzida em textos veiculados pela mídia e pelo próprio ambiente educacional - a respeito da precariedade da qualidade da educação no país (linha 1: "a educação está muito precária em nosso país.").

\section{Redação 1 - "O valor da Educação"}

\begin{tabular}{|cc|}
\hline 1 & A educação está muito precária em nosso país. \\
2 & Aqui no Brasil poucas pessoas tiveram oportunidade de ter acesso à \\
3 & escola o que acontecia muito antigamente. E a fala certamente "errada" e \\
4 & a forma de escrever foi porque nunca tiveram a oportunidade de ir à \\
5 & escola e de muito menos aprender em casa porque muitos tiveram que \\
6 & trabalhar. E hoje em dia as pessoas tem acesso a uma alfabetização, tem \\
7 & a oportunidade de ler e escrever. \\
8 & O ensino da escrita é importante porque além de você ter a \\
9 & necessidade de saber escrever, saber falar direito, você vai ser muito \\
10 & respeitado. Falar e escrever bem é a chave principal para a pessoas \\
11 & chegar em algum lugar. Até mesmo porque você não pode falar errado \\
12 & diante de um intelectual respeitado, por exemplo. Tem até cursos \\
13 & disponíveis para falar com vários tipos de pessoa. \\
14 & Vejo na TV pessoas falando errado, não dizendo as palavras corretas \\
15 & por completo, puxam demais as palavras, até esquecem de acrescentar o \\
16 & "S", o "R", quando necessário. São pessoas que dá para ver claramente \\
17 & que não teve acesso à escola. Por isso que muitos pais hoje em dia \\
18 & cobram dos seus filhos para ter uma boa educação. Porque sem educação \\
19 & hoje em dia, não dá. É muita palavra coloquial. \\
\hline
\end{tabular}

O ponto de vista negativo do escritor sobre a qualidade do ensino brasileiro é defendido e mantido por todo seu texto. Com o intuito de sustentar sua tese inicial, o aluno traz, ao longo de sua redação, conceitos aparentemente provenientes do discurso da Gramática Tradicional (GT), quando: (i) enfatiza a fala/escrita "errada" (linhas 3-4) e defende a hipótese de que falar e escrever bem é a chave principal para o alcance do sucesso (linhas 10-11); (ii) compara a fala incorreta ao não acesso 
à escola (linhas 16-19) e (iii) ressalta a existência de "muita palavra coloquial" (linha 19). O posicionamento do autor nos remete à visão estigmatizada das variedades que se distanciam da norma padrão da língua portuguesa, já que, a fim de impor seu argumento, ele enfatiza a importância do ensino da escrita correta. Além disso, há a formulação de significados argumentativos que se encadeiam no diálogo entre o autor do texto e as crenças e estereótipos da sociedade e da cultura nas quais se insere. O discurso ideológico da gramática tradicional também se encontra na redação em questão e parece conceder ao argumento autoridade, cientificidade e competência (BRETON, 2003), pois legitima as regras convencionais de uso da escrita em língua portuguesa.

O movimento dialógico com o discurso da gramática tradicional segue pelo texto e reforça posicionamentos ideológicos voltados a concepções baseadas no senso comum e em preconceitos linguísticos e sociais, o que contribui para enfatizar que a neutralidade no discurso é um mito (KOCH, 2011), pois não existe discurso fora de um contexto de produção e sem uma ideologia que o institua. As diversas ocorrências de momentos apreciativos revelam que, para o escritor, existem duas realidades excludentes: a vivida pelas pessoas que "falam errado" e a representada pelos "intelectuais". A ênfase no item lexical "saber" (duas ocorrências na linha 9) demonstra que o conhecimento formal, isto é, o adquirido na escola, é mais importante do que os saberes cotidianos, que são menosprezados.

A estrutura enunciativo-argumentativa do escritor sugere a necessidade do domínio da fala e da escrita (alinhada à variedade padrão da língua portuguesa) por parte do escritor para que ele possa ser socialmente respeitado, fato que ilustra seu posicionamento com base no preconceito linguístico e social (linhas 11-12). O argumento é voltado para uma opinião culturalmente aceita como comum e o preconceito se reproduz e enraíza, gerando uma ideia que pode vir a ser socialmente aceita, conforme evidenciado pelo uso do pronome "você" (linhas 8, 9 e 11), que é um elemento indicativo da inclusão do outro-enunciatário na sustentação do argumento e na manutenção do posicionamento argumentativo. Ao lidarmos com as esferas dialógicas dos enunciados do autor, observamos que a todo e qualquer discurso subjaz uma ideologia (BAKHTN, 
2003; KOCH, 2011), já que a escrita argumentativa contribui para a formulação de argumentos baseados em enunciados sociais, advindos de diferentes contextos de interação. Nesse sentido, entendemos que a redação 1 reflete e refrata a realidade em um contínuo movimento interativo e intertextual.

Os discursos produzidos pelo escritor no terceiro parágrafo, assim como nos anteriores, ilustram as vozes utilizadas no estabelecimento de pontos de argumentação, elaborados com base em enunciados repletos de escolhas avaliativas e de vozes tecidas por preconceitos e estereótipos sociais. $\mathrm{O}$ exemplo usado pelo estudante no início do terceiro parágrafo ("Vejo na TV", linha 14) demonstra como ele se expõe de forma negativa em relação às pessoas que não falam corretamente a língua portuguesa - por meio do uso de um discurso que nos reporta à visão da gramática tradicional em diálogo com a do preconceito linguístico e social.

Ainda no mesmo trecho, notamos que a argumentação é fundamentada em um exemplo pessoal sob a aparência de uma única voz e os enunciados são baseados em uma situação particular do enunciador. Ao trazer sua experiência para o texto, o aluno expõe seu testemunho, dialogando com o contexto cultural que o cerca, do mesmo modo que estabelece um movimento de (inter)relação entre o eu e o nós (KOCH, 2011). O escritor também descreve o testemunho de outra pessoa ("São pessoas [...] uma boa educação.", linhas 16-18), isto é, do outro-interlocutor, e revela sua opinião que é compartilhada com o seu leitor. Evidencia-se a intertextualidade e a relação dialógica com diferentes discursos sociais que, ao se complementarem, explicitam o posicionamento argumentativo e ideológico do autor do texto. Ou, como afirma Barros (1999, p. 6), percebe-se o "embate de muitas vozes sociais que se deixam escutar.".

O segundo texto, assim como o primeiro, caracteriza-se como um espaço de interação de múltiplas vozes sociais que cria e mantém o posicionamento argumentativo do autor quanto ao tema de sua redação: a crença de que "a escola tem a função de ensinar, educar, dar o respeito e exigir o respeito do próximo" (linhas 1 e 2), quase com a responsabilidade exclusiva pela formação geral do sujeito. 
Redação 2 - "O bom português"

\begin{tabular}{cc|}
1 & A escola tem a função de ensinar, educar, dar o respeito e exigir o \\
2 & respeito do próximo. No Brasil, a sociedade em geral preocupa-se em \\
3 & aprender a língua estrangeira, como por exemplo o inglês, que é o mais \\
4 & procurado e exigido por muitas empresas, sendo que, a sociedade \\
5 & "esquece que" muitos não sabem nem falar o português, escrever o \\
6 & português direito e tem que "forçadamente" aprender a língua alheia. \\
7 & A sociedade, não dá a devida importância a língua portuguesa, a \\
8 & cultura brasileira. Estão mais preocupados com o que acontece na \\
9 & Europa e em outros continentes, do que com o seu país, a sua cidade, a \\
10 & sua educação. \\
11 & Deveria-se criar uma lei que funcionasse realmente com o seguinte \\
12 & tema: "O bom português, para o bom brasileiro bilíngue", ou seja, aquele \\
13 & que melhor souber falar, se expressar bem no português, "ganharia" \\
14 & gratuitamente um curso de língua estrangeira de sua preferência, \\
15 & com o direito de sair, já empregado do curso. Só assim (talvez) o Brasil, \\
16 & passaria a se interessar mas no português e no que ganhariam em troca. \\
\hline
\end{tabular}

De acordo com as ideias apresentadas pelo aluno em sua redação, a sociedade não valoriza aquilo que possui, isto é, “(...) a língua portuguesa, a cultura brasileira (...) o seu país, a sua cidade, a sua educação" (linhas 7-10). Nessa constatação, encontramos um ponto de argumentação elaborado no entrelaçar de vozes sociais ideológicas. O escritor avalia de modo negativo o fato de que muitos brasileiros ainda nem sabem o português momento em que constrói uma opinião baseada no preconceito linguístico e social. Verificamos que, além disso, existe a ênfase na perspectiva de língua como um fenômeno homogêneo e o aluno se expressa com um discurso aparentemente veiculado pela gramática tradicional, uma vez que a mesma tende a padronizar a língua. Para reforçar seu posicionamento autoral, o aluno também apresenta uma avaliação negativa do comportamento da sociedade, através de uma estrutura argumentativa de autoridade trazida pelo discurso empresarial: "No Brasil, a sociedade em geral preocupa-se em aprender a língua estrangeira, como por exemplo o inglês, que é o mais procurado e exigido por muitas empresas (...)." (linhas 2-4).

Com intuito de estabelecer um vínculo dialógico, o estudante exemplifica uma realidade que para ele atinge a sociedade em geral: “(...) a sociedade 'esquece' que muitos não sabem nem falar o português, escrever o português direito e tem que 'forçadamente' aprender a língua alheia." (linhas 4-6). Temos a formação de um ponto de argumentação que se estabelece no confronto entre as exigências do mercado (linha 4) e a realidade 
da população (linhas 5-6). Existe, nesse momento, a produção de um enunciado que ecoa uma postura contrária ao ensino de língua estrangeira sem que haja antes uma boa formação da língua portuguesa. Portanto, crenças sociais e posicionamento autoral são associados a discursos ideológicos, pois parece que o escritor entende que falantes que não "sabem" a sua própria língua não terão capacidade para aprender uma nova.

O terceiro parágrafo (linhas 11-16) introduz um novo ponto de argumentação - a criação de uma lei para "o bom brasileiro bilíngue" (linhas 11-12) - que reproduz vozes provenientes do discurso pedagógico. A sugestão de tal lei representa uma visão compensatória de ensino de língua, já que o escritor enfatiza a premiação de uma língua estrangeira para os que sabem o "bom português". Ao formular seu posicionamento com uma opinião comum (BRETON, 2003), ou seja, com a crença social de que o brasileiro não sabe falar bem o português, o estudante estabelece um diálogo com o contexto imediato (escola) e o mais amplo (sociedade), conferindo a seu enunciado a materialidade da realidade, resgatando e reproduzindo diferentes discursos ideológicos inerentes ao ato de argumentar $(\mathrm{KOCH}, 2011)$. Do mesmo modo, verificamos um forte pensamento ideológico no uso do adjetivo "bom" em "bom brasileiro bilíngue" e "bom português" que indica a possibilidade de haver, em contrapartida, um "mau" brasileiro ou um português "ruim".

Com isso, o autor tenta apresentar uma solução para a questão que vem discutindo no decorrer de seu texto por intermédio de uma concepção tradicional de linguagem, já que a recompensa seria para os que desempenharem determinado comportamento, isto é, para "aquele que melhor souber falar, se expressar bem no português" (linhas 12-13). Além disso, percebemos que, nas linhas 15-16, há a afirmação de que a recompensa poderia trazer benefícios para os brasileiros, que passariam a se interessar mais pelo português. Essa afirmação é constituída por opiniões fundamentadas no senso comum e na realidade sociocultural do escritor, que retorna seu discurso ideológico ao contexto sociocultural, em um movimento dialógico.

Ao discutirmos os textos das Redações 1 e 2 como fenômenos sociodiscursivos, isto é, como enunciados concretos e espelhos de uma determinada cultura, buscamos ressaltar a recorrência de enunciações estereotipadas na construção dos 
argumentos, fato que, muito provavelmente, pode ser justificado pela esfera ideológica na qual o tema "escrita e inclusão social" exposto na redação se insere.

Sem a intenção de rotular os tipos de discursos componentes dos textos investigados, identificamos e nomeamos as vozes mais frequentes na produção escrita observada. Sabemos, contudo, que tal classificação é meramente ilustrativa, pois vozes sociais constituem e são constituídas por outras vozes que, em uma cadeia, compõem a pluralidade discursiva.

Assim sendo, e tendo em vista que os pontos de argumentação são formados por vozes originárias de enunciados ideológicos, sugerimos uma correlação entre as vozes ressaltadas nas redações discutidas e os tipos de argumentos estipulados por Breton (2003):

Figura 1 - Vozes sociais e argumentação.

\begin{tabular}{|c|c|c|}
\hline \multicolumn{2}{|c|}{ VOZES SOCIAIS E ARGUMENTAÇÃO } \\
\hline \multirow{2}{*}{ Argumentos } & Competência & Voz da gramática tradicional \\
\hline \multirow{4}{*}{ Autoridade } & Experiência & Voz do eu e voz do nós \\
\cline { 2 - 3 } & Testemunho & Voz do eu e voz do nós \\
\hline \multirow{3}{*}{$\begin{array}{c}\text { Pressupostos } \\
\text { Comuns }\end{array}$} & Opinião Comum & $\begin{array}{c}\text { Voz do senso comum e voz do } \\
\text { preconceito linguístico e social }\end{array}$ \\
\cline { 2 - 3 } & Valores Comuns & Voz do discurso pedagógico \\
\hline
\end{tabular}

A possível relação entre os tipos de argumentos enumerados por Breton (2003) e os tipos de vozes que identificamos nesta pesquisa indica uma correspondência entre os argumentos de autoridade e a "voz da gramática tradicional", a "voz do eu" e a "voz do nós". Mais especificamente, a "voz da gramática tradicional" está relacionada aos argumentos de competência, que pressupõem uma autoridade científica, na qual há a legitimação de uma opinião. Como vimos, a reprodução do discurso da GT é frequente nas duas redações, uma vez que reforçam a prescrição do saber correto/ adequado em oposição ao incorreto/ inadequado. A "voz do eu" e a "voz do nós", por sua vez, correspondem aos argumentos que estão baseados em experiências vivenciadas pelo enunciador na 
proposição de seus argumentos (enunciado aparentemente monológico) ao mesmo tempo em que podem estar ligadas ao testemunho vivenciado por alguém (enunciado dialógico). Em outras palavras, e de acordo com Koch (2011), é na dinâmica da interação verbal que ao nos constituirmos como "eu", estamos, também, constituindo o "outro", que é por sua vez constitutivo do próprio "eu".

Por outro lado, a "voz do senso comum", a " voz do preconceito linguístico e social" e a "voz do discurso pedagógico" estão mais atreladas aos pressupostos comuns. Associamos a "voz do senso comum" e a do "preconceito linguístico e social" aos argumentos baseados em um pensamento comum, pois são, normalmente, opiniões culturalmente compartilhadas. Essa ideia pode dialogar com enunciados que perpetuem o discurso da gramática tradicional, em sua apresentação de avaliações negativas do uso "padrão" da língua por seus falantes. A "voz do discurso pedagógico" está atrelada aos argumentos baseados em valores comuns a um determinado contexto imediato ou amplo, que se ligam a apreciações de uma dada comunidade, em nosso caso, a comunidade educacional. Logo, podemos dizer que a ideologia inerente de todo e qualquer discurso $(\mathrm{KOCH}, 2011)$ contribui para a formulação de argumentos pautados em discursos sociais originários de diferentes esferas da comunicação humana.

Apesar de percebermos que essas vozes estão presentes nos enunciados das redações, compreendemos que, possivelmente, os escritores não têm consciência dos discursos que estão (re)produzindo. Reforçamos que seus textos surgem em resposta a enunciados anteriores e a outros que ainda estão por vir, e que o diálogo evidenciado nas redações reflete o contexto situacional do qual os estudantes fazem parte, abrangendo a realização da linguagem e a criação de possíveis sentidos de uma dada cultura.

\section{Considerações finais}

O propósito de nossa análise foi observar o diálogo entre as vozes sociais e a argumentação, identificando a (re)produção de ideologias em redações escolares. A partir da análise dos dados, encontramos a recorrência de enunciados ideológicos originários da gramática tradicional, do preconceito linguístico 
e social, do senso comum e do discurso pedagógico, estando todos eles relacionados à voz da experiência particular (voz do eu) em diálogo com os demais enunciados da sociedade (voz do nós). Com isso, foi possível perceber que, ora os alunos produzem enunciados através da produção de uma linguagem constituída por meio do caráter dialógico da linguagem -, e ora produzem textos mais monológicos - que se caracterizam aparentemente como um enunciado de voz única. Apesar de ter sido possível encontrarmos a linguagem mais monológica, acreditamos que, mesmo quando o enunciado é composto por uma única voz, ele sofre a influência de outros discursos, assim como os influencia.

Dessa forma, chegamos à consideração de que todos os enunciados são formados por posicionamentos ideológicos, presos a crenças sociais que constituem os argumentos dos autores-escritores e, em consequência, formam os seus pontos de vista acerca do tema abordado na redação. Ainda que os alunos possam não ter consciência de que seus enunciados são compostos por crenças e estereótipos, salientamos que a natureza estritamente dialógica da linguagem permite evidenciar as marcas ideológicas inerentes à criação dos discursos formados.

Por fim, sugerimos que a investigação das duas redações, retiradas de um corpus com características muito semelhantes às encontradas neste estudo, nos permite afirmar que as vozes aqui identificadas são, em sua essência, argumentativas, pois servem ao intuito de convencer e persuadir o leitor e, além disso, reiteramos que os argumentos se constituem com base em vozes ideológicas que contribuem para o posicionamento autoral.

\section{REFERÊNCIAS}

ABREU, A. R. Vozes de julgamento como pontos de argumentação na produção escrita de alunos do ensino médio: abordagem sociodiscursiva e sociossemiótica. Dissertação de Mestrado Departamento de Letras, Pontifícia Universidade Católica do Rio de Janeiro, Rio de Janeiro, 2013.

BAKHTIN, M. M. (VOLOCHINOV, V. N.). Marxismo e Filosofia da Linguagem: problemas fundamentais do método sociológico na ciência da linguagem. Trad. Michel Lahud e Yara Frate. 5 ed. São Paulo: Hucitec/UNESP, 1990[1929]. 
BAKHTIN, M. Estética da Criação Verbal. Tradução Paulo Bezerra. 4 ed. São Paulo: Martins Fontes, 2003.

BARROS, D. L. P. Dialogismo, polifonia e enunciação. In: BARROS, D. L. P.; FIORIN, J. L. (orgs.) Dialogismo, Polifonia, Intertextualidade: em torno de Bakhtin. São Paulo: Editora da Universidade de São Paulo: 1999, p. 1-9. (Ensaios de Cultura, 7) BEZERRA, P. Polifonia. In: BRAIT, B. (org.) Bakhtin: conceitoschave. São Paulo: Contexto, 2005, p. 191-200.

BRAIT, B. As vozes bakhtinianas e o diálogo inconcluso. In: BARROS, D. L. P.; FIORIN, J. L. (orgs.) Dialogismo, Polifonia, Intertextualidade: em torno de Bakhtin. São Paulo: Editora da Universidade de São Paulo: 1999, p. 11-27. (Ensaios de Cultura, 7) BRETON, P. A argumentação na comunicação. Tradução Viviane Ribeiro. 2 ed. Bauru, São Paulo: EDUSC, 2003.

DENZIN, N. K.; LINCOLN, Y. S. O planejamento da pesquisa qualitativa: teorias e abordagens. 2 ed. Porto Alegre: Artmed, 2006. FARACO, C. A. Linguagem \& Diálogo: As ideias linguísticas do Círculo de Bakhtin. São Paulo: Parábola, 2013.

FREITAS, M. T. Vygotsky e Bakhtin. Psicologia e educação: um intertexto. 4 ed. São Paulo: Ática, 2000.

JUNQUEIRA, F. G. C. Confronto de vozes discursivas no contexto escolar: percepções sobre o ensino de gramática da língua portuguesa. Dissertação de Mestrado - Departamento de Letras, Pontifícia Universidade Católica do Rio de Janeiro, Rio de Janeiro, 2003.

KOCH, I. G. V. Argumentação e linguagem. 13 ed. São Paulo: Cortez, 2011.

MIOTELLO, V. Ideologia. In: BRAIT, B. (org.) Bakhtin: conceitoschave. São Paulo: Contexto, 2005, p. 167-176.

NÓBREGA, A. N. 'Teacher', posso te contar uma coisa? A conversa periférica e a sócio-construção do conhecimento na sala de aula de língua estrangeira. Dissertação de Mestrado Departamento de Letras, Pontifícia Universidade Católica do Rio de Janeiro, Rio de Janeiro, 2003.

RODRIGUES, R. H. Os gêneros do discurso na perspectiva dialógica de linguagem: a abordagem de Bakhtin. In: MEURER, J. L.; BONINI, A.; MOTTA-ROTH, D. (orgs.) Gêneros: teorias, métodos, debates. São Paulo: Parábola Editorial, 2005, p.152-183. 


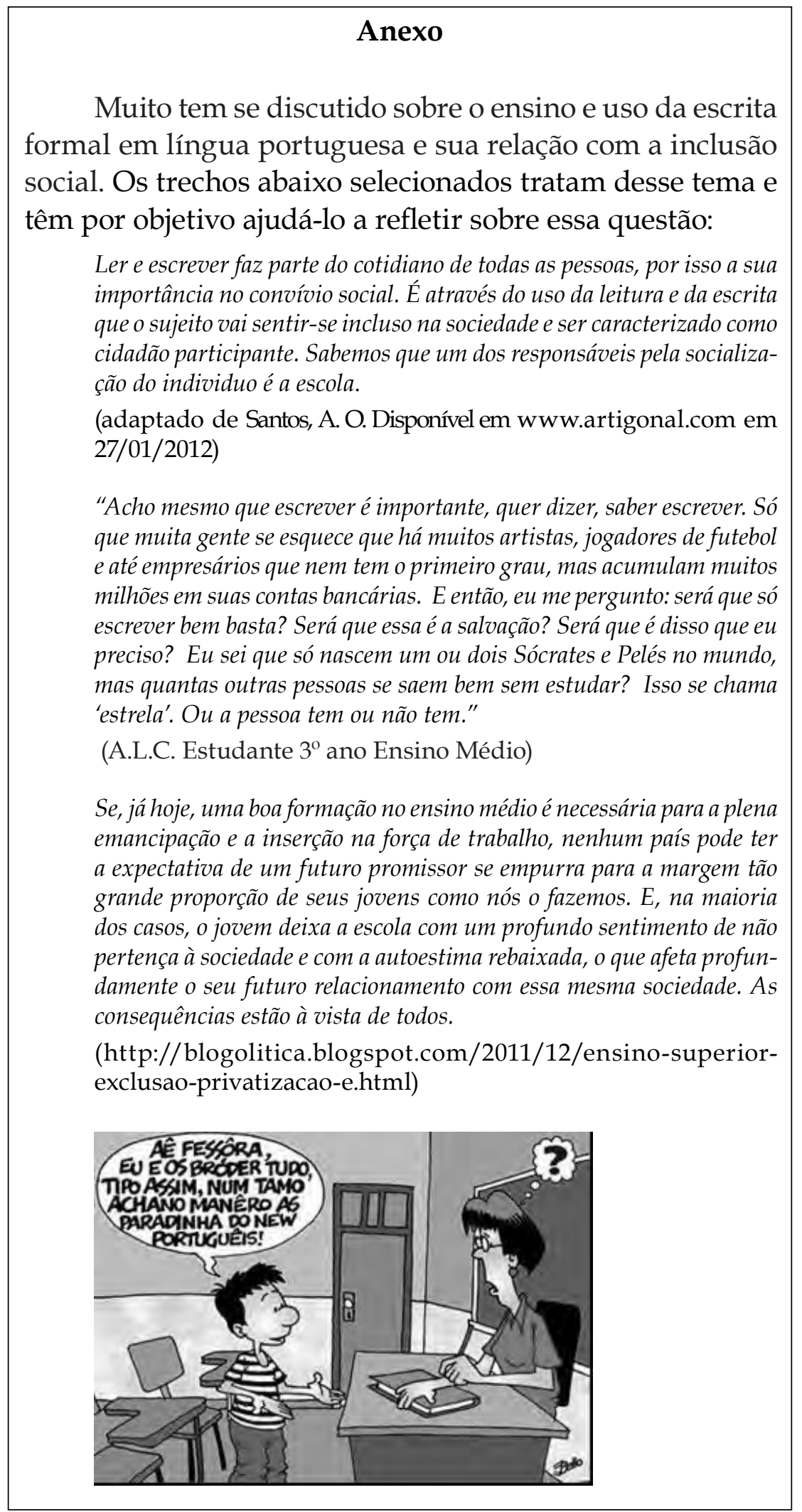




\section{Abstract}

Argumentative voices and authorial positioning in school written production

In this article, we examine school written production according to a possible relationship between voices and argumentative positioning. The way voices reflect and refract the ideological positioning of the student-writer will also be investigated. Our purpose is to discuss the dialogue between discursive voices and argumentation in school writing and identify how dialogic discourse (re)produce ideologies of a certain culture. The study is based on theoretical principles from a social-discursive approach, proposed by the Bakhtin Circle, in interface with a social perspective of argumentation. Two argumentative texts were taken from a corpus composed by 50 compositions. The analysis followed a qualitative methodology in order to illustrate how discourses produced in the texts bring ideologies which create authorial positioning. Results indicate that the texts are permeated by a large number of voices which are used to build the writer's arguments and point of view.

Key-words: Written production; Voices; Argumentation; Authorial positioning 